\title{
Putting the text back into context: toward increased use of mixed methods for quality of life research
}

\author{
Lena Ring • Cynthia R. Gross · Elaine McColl
}

Accepted: 17 March 2010/Published online: 27 April 2010

(C) Springer Science+Business Media B.V. 2010

Much of the research in quality of life (QoL), and the majority of publications in Quality of Life Research, have employed quantitative methods. Although these methods have value in facilitating rigor and reproducibility in clinical research studies, they have a concomitant risk of losing the subtlety and distinctions experienced by patients living with health problems. The field of QoL research would benefit from an increased awareness of the value of combining qualitative and quantitative approaches and from a renewed appraisal of best practices in the use of such mixed methods.

Qualitative frameworks and techniques for data collection offer a wide array of options for studying the lived experience of a disease and its treatment. Frequently used qualitative approaches to collect and analyze data and interpret results include phenomenology, grounded theory, and ethnography [1]. These approaches differ with regard to their essence. Phenomenology aims to understand the meaning of persons' experiences. Grounded theory builds new theory and concepts from the ground up. Ethnography

\footnotetext{
L. Ring $(\bowtie)$

Uppsala University, Uppsala, Sweden

e-mail: Lena.Ring@farmaci.uu.se

L. Ring

AstraZeneca, R\&D, HEOR, Sweden

C. R. Gross

College of Pharmacy and School of Nursing,

University of Minnesota, Minneapolis, MN, USA

e-mail: gross002@umn.edu

E. McColl

Institute of Health and Society, Newcastle University,

21 Claremont Place, Newcastle upon Tyne NE2 4AA, UK

e-mail: e.mccoll@newcastle.ac.uk
}

focuses on understanding "insider points of view" within a specific cultural or social group context. Qualitative data can be collected in a variety of ways, such as by in-depth interviews, focus groups, observation, and document evaluation. Important aspects to consider for enhancing the rigor of qualitative research are the criteria for selecting participants, determining sample size, establishing validity, controlling biases, and conducting the qualitative analyses. These aspects have all been described in texts, but guidance and oversight by an experienced qualitative researcher may be an optimal way to learn these skills and to choose the appropriate framework and methods [2]. Full reporting of how the work was done is also essential, and building on existing qualitative-specific criteria can be helpful [3-5].

Qualitative research has long been accepted in anthropology and sociology. In contrast, the emergence of qualitative research within the health field has triggered controversy. In a chapter on qualitative methods in health technology assessment, Murphy and Dingwall recount the key issues and positions that comprised this controversy [6]. Using quotes from thought leaders, they illustrate the views of opposing sides in the debate that pitted holistic social constructivism against hypothesis-driven empiricism during the 1980s and 1990s. Hypothesis-driven empiricism, the orderly system also known as "the scientific method," was challenged as being only one viewpoint"post-positivism". Alternative viewpoints, such as social constructivism, were argued to provide a better framework for understanding complex issues, such as health $[6,7]$. Some asserted that qualitative and quantitative methods arose from "radically incompatible" worldviews with such pervasive differences that a "separatist" viewpoint was the only option. It was common for faculty and students in graduate programs to take sides and be labeled (willingly or unwillingly) as either qualitative or quantitative people. 
Individual battles were fueled by language-a vocabulary filled with unfamiliar words (e.g., etic, emic, Hermeneutics), and familiar words given unfamiliar meanings (e.g., sampling, rich).

Fortunately, it appears that in recent years the paradigm wars have lost much of their heat. Newer editions of methodology texts have first added, and then expanded content on qualitative approaches, and it is now the norm for graduate students to be encouraged to acknowledge the literature, if not to gain hands-on skills and experience, in both qualitative and quantitative approaches $[8,9]$. The post-positivist's randomized clinical trial could determine which medication was superior for the average patient, and the social constructionist could interview individual patients and their caregivers in order to understand what it means to live with the disease and its treatment. The complementary nature of these endeavors is increasingly recognized in the literature $[10,11]$. There are excellent examples of interdisciplinary teams bringing both qualitative and quantitative approaches to bear on complex health problems [12,13], and overall, the number of articles containing qualitative research in MEDLINE has increased more than fourfold between 1980-1984 and 2006-2010 (see Fig. 1).

Mixed methods are founded in pragmatism, using whatever rigorous approach works to gain useful insights [14]. Mixed methods enable us to place research efforts on a continuum from purely qualitative to purely quantitative, with intermediate points reflecting studies that have a blend of both. At the purely qualitative end of the spectrum, many studies demonstrate the use of constructivist grounded theory and involve in-depth interviews with a small number of people with a particular condition [15]. This approach allows for an in-depth exploration of the patient's

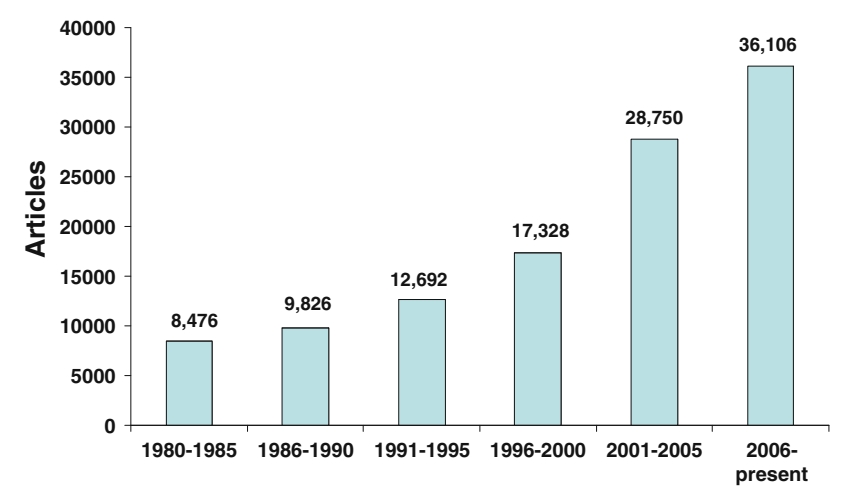

Fig. 1 Qualitative research in MEDLINE, 1980 to present. The number of articles containing qualitative research published in the biomedical literature in each 5-year epoch from 1980 to the present was estimated using the number of articles retrieved by the following search strategy: (qualitative* or phenomenolog* or grounded theor* or ethnograph*).mp. [mp = title, original title, abstract, name of substance word, subject heading word, unique identifier] (120904). MEDLINE search conducted March 2, 2010 perspective of factors influencing their QoL. The disadvantage of this approach is that its external validity or generalizability is likely quite limited.

Other researchers employ both quantitative and qualitative methods, in varying proportions, either in parallel or in sequence. The expectations of regulatory authorities such as the Food and Drug Administration (FDA) and the European Medicines Agency (EMA) regarding the establishment of evidence of content validity for patient-reported outcomes have served to both drive and legitimize mixed-method interdisciplinary efforts $[16,17]$. Content validity needs to be established from patients' own perceptions and hence qualitative methods are the preferred approach to generating item content for new patient-reported outcome measures in the target population. Examples of this approach utilize focus groups and cognitive interviews (qualitative) in developing and refining a new measure prior to applying classic or modern psychometric methods to establish validity and reliability (quantitative) [18]. This mixed-method approach has been adapted by the PROMIS investigators in their model of item-pool development [19].

Recently, in $Q L R$, Robertson et al. [20] used in-depth interviews to explore the frames of reference used by a subsample of respondents to QoL measures in a large randomized controlled trial while Wolfe and Sirois [21] performed content analysis on the responses to the open-ended question "How has inflammatory bowel disease affected your daily activities?", embedded within a structured crosssectional survey of the well-being of people with inflammatory bowel disease (quantitative then qualitative).

Scientific rigor is required in the application and reporting of any methods, whether qualitative or quantitative [11]. As researchers in the field of QoL research grow to embrace the use of mixed methods, the need for qualified reviewers becomes more pressing. It would thus be important to expand the continuing-education opportunities at ISOQOL meetings to teach, discuss and disseminate current best practices in mixed methods [22]. Further, this would enable the $Q L R$ journal to have a cadre of reviewers who are qualified to judge and provide useful constructive feedback on the hopefully growing stream of mixedmethod manuscripts.

\section{References}

1. Denzin, N. K., \& Lincoln, Y. S. (Eds.). (2005). The SAGE handbook of qualitative research (3rd ed.). Thousands Oaks, CA: Sage.

2. Morse, J. M., Swanson, J. M., \& Kuzel, A. J. (Eds.). (2001). The nature of qualitative evidence. Thousand Oaks, CA: Sage.

3. The equator network: Enhancing the QUAlity and Transparency of health Research. [cited 2010 February 18, 2010]; Available from: http://www.equator-network.org/home/ 
4. Elliott, R., Fischer, C. T., \& Rennie, D. L. (1999). Evolving guidelines for publication of qualitative research studies in psychology and related fields. British Journal of Clinical Psychology, 38(3), 215-229.

5. Tong, A., Sainsbury, P., \& Craig, J. (2007). Consolidated criteria for reporting qualitative research (COREQ): A 32-item checklist for interviews and focus groups. International Journal for Quality in Health Care, 19(6), 349-357.

6. Murphy, E., \& Dingwall, R. (2001). Qualitative methods in health technology assessment. In A. Stevens, et al. (Eds.), The advanced handbook of methods in evidence based healthcare (pp. 166179). Thousand Oaks, CA: Sage.

7. Lincoln, Y. S. (1990). The making of a constructivist: A remembrance of transformations past. In E. Guba (Ed.), The paradigm dialogue (pp. 67-87). Newbury Park: Sage.

8. Creswell, J. W. (2009). Research design: Qualitative, quantitative and mixed methods approaches (3rd edn ed.). Thousand Oaks, CA: Sage.

9. Locke, L. F., Spirduso, W. W., \& Silverman, S. J. (2006). Proposals that work: a guide for planning dissertations and grant proposals (5th ed.). Thousand Oaks, CA: Sage.

10. Hohmann, A. A., \& Shear, M. K. (2002). Community-based intervention research: coping with the "noise" of real life in study design. American Journal of Psychiatry, 159, 201-207.

11. Pope, C., \& Mays, N. (2009). Critical reflections on the rise of qualitative research. BMJ, 339, 3425.

12. Mendlinger, S., \& Cwikel, J. (2008). Spiraling between qualitative and quantitative data on women's health behaviors: a double helix model for mixed methods. Qualitative Health Research, 18, 280-293.

13. Goldsmith, M. R., Bankhead, C. R., \& Austoker, J. (2007). Synthesizing quantitative and qualitative research in evidencebased patient information. Journal of Epidemiology and Community Health, 61, 262-270.

14. Johnson, R. B., Onwuegbuzie, A. J., \& Turner, L. A. (2007). Toward a definition of mixed methods research. Journal of Mixed Methods Research, 1(2), 112-133.
15. Malm, D., \& Hallberg, L. R. M. (2006). Patients' experiences of daily living with a pacemaker. A grounded theory study. Journal of Health Psychology, 11, 787-798.

16. EMEA. (2005). Reflection paper on the regulatory guidance for the use of health-related Quality of life (HRQL) measures in the evaluation of medicinal products, London, 27 July 2005. Committee for Medicinal Products for Human Use (CHMP). Doc. Ref. EMEA/CHMP/EWP/139391/2004. 2005. London: EMEA.

17. FDA. (2009). US Food and Drug Administration. Guidance for Industry: Patient-Reported Outcome Measures: Use in Medical Product Development to Support Labeling Claims. Available from:http://www.fda.gov/Drugs/GuidanceComplianceRegulatory Information/Guidances/ucm064981.htm (Patient-Reported Outcome Measures: Use in Medical Product Development to Support Labeling Claims. Final. Issue date 12/8/2009). [Accessed Jan 26, 2010].

18. Mast, T. C., et al. (2009). Development and psychometric properties of the HPV impact profile (HIP) to assess the psychosocial burden of HPV. Current Medical Research and Opinion, 25(11), 2609-2619.

19. PROMIS. Patient-Reported Outcomes Measurement Information System. [cited 2010 February 18]; Available from: http://www. nihpromis.org/.

20. Robertson, C., Langston, A. L., Stapley, S., McColl, E., Campbell, M. K., Fraser, W. D., et al. (2009). Meaning behind measurement: Self-comparisons affect responses to health-related quality of life questionnaires. Quality of Life Research, 18(2), 221-230.

21. Wolfe, B. J. S., \& Fuschia, M. (2008). Beyond standard quality of life measures: The subjective experiences of living with inflammatory bowel disease. Quality of Life Research, 17(6), 877-886.

22. Brod, M., Tesler, L. E., \& Christensen, T. L. (2009). Qualitative research and content validity: Developing best practices based on science and experience. Quality of Life Research, 18(9), 12631278. 